\title{
Movimiento ambientalista canadiense y libre comercio*
}

\author{
Sofía Gallardo C. \\ División de Estudios Internacionales \\ Centro de Investigación \\ y Docencia Económicas
}

Resumen

La crisis económica de principios de la década de los ochenta en Canadá, favoreció la organización de grupos sociales preocupados por la justicia, la equidad y el bienestar. El movimiento ambientalista se manifestó en contra de la adopción de políticas de corte neoliberal en los terrrenos social y económico. Se opuso a la relajación de las leyes de protección ambiental y las prácticas económicas que lo dañan en nombre de la competitividad comercial.

El movimiento ambientalistacanadiensetiene una base social amplia y abarca un espectro plural de posiciones ideológicas que van desde el conservacionismo mediador hasta el ecologismo más radical. En su mayoría han protestado y hecho "abogacía social" en contra de lo que consideran un statu quo injusto. Se han enfrentado con trabas burocráticas y legales, así como con intereses económicos y políticos que retardan o evitan la aplicación de muchas de sus propuestas. Algunos de ellos han influido a la opinión pública a través de los medios masivos de comunicación, propagando 
información sobre problemas ambientales y buscando un cambio de actitud en las formas de vida de la sociedad moderna.

Como en otras naciones, las organizaciones canadienses enfrentan el problema de sobrevivir financieramente y evitar al mismo tiempo la cooptación por parte del Estado o las industrias. En los años noventa han logrado importantes avances, junto con los movimientos ambientalistas de México y Estados Unidos, para que los tres gobiernos reconozcan explícitamente las implicaciones mutuas entre la integración comercial y la naturaleza global de los problemas ambientales bajo el Tratado de Libre Comercio de América del Norte.

Introducción

La preocupación por la calidad del medio ambiente alcanzó proporciones significativas en los años sesenta y setenta en América del Norte y Europa, dando lugar al surgimiento de nuevos movimientos sociales. A diferencia de otros, el movimiento ambientalista ha trascendido como un fenómeno social que ha reorientado el comportamiento, las actitudes y las percepciones de las sociedades. ${ }^{1}$

A mediados de los años ochenta y principios de los noventa, los grupos ambientalistas canadienses y las redes sociales reconocieron públicamente la existencia de implicaciones mutuas entre los acuerdos comerciales y la naturaleza global de los problemas ambientales. Su movilización generó un proceso social que va mas allá del Acuerdo de Libre Comercio de Estados Unidos y Canadá (ALCEUC) y de las negociaciones del Tratado de Libre Comercio de América del Norte (TICAN). Además, propusieron

' Varios estudiosos observan el fenómeno como una revolución(Nicholson, 1970; Pearce, 1991; y Sale, 1993). En Canadá, el movimiento separatista es el único que ha eclipsado la importancia política progresistadel ambientalismo (Paehlke, 1989). Ya sea que el movimiento ambientalista permanezca como el trabajo de organizaciones ambientalistas o se integre completamentea la política convencional, es probableque la ecología continúe siendo una de las preocupaciones sociales más importantes (Barr, 1995). establecer un régimen ecológico regional asociado con pautas de desarrollo prevalecientes y alternativas.

Este artículo intenta explicar por qué y cómo el movimiento ambientalista canadiense se organizó para participar y presionar en las negociaciones comerciales. La primera parte contiene una revisión de las filosofías, acciones, organización, y situación actual del movimiento ambientalista canadiense. La segunda se concentra en las prácticas de abogacía de los ambientalistas canadienses. La tercera y aarta partes se ocupan de la organización y las posiciones de los movimientos social y ambientalista canadienses frente al ALCEUC y al TLCAN. Las reflexiones finales contrastan brevemente la experiencia de esos movimientos frente al libre comercio con la teoría de los nuevos movimientos sociales. Este artículo está basado en investigaciones previas sobre el tema general (Gallardo, 1993, 1994, 1995 y 1997), en fuentes primarias canadienses y literatura secundaria del dominio público o de circulación restringida.

\section{Panorámica del movimiento ambientalista canadiense}

La preocupación actual de la humanidad sobre la capacidad de sustentabilidad planetaria es la expresión más reciente del antiguo interés del hombre por la preservación del mundo natural y del deseo de mejorar el medio ambiente en el que habita.

\section{Filosofías}

Hay un amplio espectro de filosofías que influyen en la organización y las tádticas del movimiento ambientalista canadiense. La gran efervescencia intelectual y algunas de las inquietudes de la comunidad ambientalista durante la década pasada poseen raíces filosóficas antiguas (Altmeyer, 1976). El pensamiento ambiental contemporáneo en Canadá tiene tres vertientes: conservacionismo, ecologismo y ambientalismo ${ }^{2}$ (Macdonald, 1991; Paehlke, 1989). El conservacionismo se refiere al manejo adecuado de los recursos naturales para asegurar la sustentabilidad de las generaciones futuras. El ecologismo gira en torno a una concepción holista que afirma los

2 En este artículo se utilizan de manera genérica los conceptos de ambientalismo, movimiento y grupos ambientalistas. cuando no se alude a su connotación específica en relación con el conservacionismo y el ecologismo. 
valores intrínsecos de la naturaleza y la unión de la humanidad con el mundo natural. El ambientalismo busca mitigar y eliminar los impactos negativos de la sociedad industrial consumista moderna. No existe necesariamente una correlación directa entre un grupo social determinado y alguna de estas líneas de pensamiento. Han surgido corrientes intelectuales que integran estas categorías en enfoques nuevos y más complejos, y algunos .grupos tienen miembros que suscriben aspectos de las tres. Esto no significa que las tres perspectivas sean redundantes. Por el contrario, la evolución del conservacionismo, el ecologismo y el ambientalismo en Canadá ofrece a los grupos ambientalistas un conocimiento extenso sobre el cual se basan.

El conservacionismo tiene raíces históricas profundas en Canadá. La popularidad creciente del ecologismo en el movimiento ambientalista ha favorecido un cambio en la concepción de las reservas naturales a la de los valores intrínsecos. Las teorías importadas como la ecología profunda comienzan a moverse del margen radical, y a jugar un papel más importante en la formación del pensamiento ambientalista canadiense. El Partido Verde representa un pensamiento novedoso y un foro político aún marginal para las nuevas filosofías ecologistas. Por último, la veta holista y espiritualista del ecologismo introduce una visión indígena del mundo en el pensamiento ambientalista. La creciente politización de las culturas nativas y los vínculos entre los temas ambientales e indígenas fortalecen el papel que la filosofía ambientalista puede llegar a jugar en los conflictos de las comunidades aborígenes con la sociedad dominante.

Estas consideraciones sobre la filosofía ambientalista ayudan a entender las motivaciones y las influencias de la gran variedad de grupos que forman el movimiento ambientalista canadiense. La mayoría de los grupos naturalistas y a favor de la vida salvaje adoptan claramente el conservacionismo como su orientación dominante,' y los grupos en el margen radical del movimiento están más influenciados por las diferentes corrientes del ecologismo. ${ }^{4} \mathrm{La}$ mayoría de los grupos ambientalistas contra la contaminación- están

${ }^{3}$ Nature Conservacy of Canada (Conservación de la Naturaleza de Canadá), Canada Nature Federation (Federación para la Naturaleza Canadá), Sierra Club Canada (Club Sierra Nature Fen Canadá), Canadian Wildife Federation (Federación Canadiense para la Naturaleza), y Ducks
Unlimited Canada (Patos Sin Límite Canadá), entre otros.

${ }^{4}$ Friends of the Earth (Amigos de la Tierra), Greenpeace y Earth First! (iPrimero la Tierra!), entre otros.

influenciados primordialmente por el ambientalismo reformado. ${ }^{5}$ Sin embargo, es un hecho que tal pureza ideológica resulta rara. Muchos de los grupos ambientalistas canadienses y los individuos que participan en ellos combinan valores del conservacionismo, ambientalismo y ecologismo (Macdonald, 1991).

\section{Grupos}

Tal como se mencionó, el movimiento ambientalista canadiense es muy diverso. Tiene alrededor de 2,000 grupos que varían desde grandes organizaciones multimillonarias autofinanciadas, hasta pequeños grupos locales con causas concretas (Gallon, 1991). Cuatrocientos de ellos aproximadamente residen en la provincia de Ontario, incluyendo a la mayoría de los que tienen más recursos económicos y reconocimiento público, como Greenpeace, World Wildlife Fund Canada (WWFC) (Fondo Mundial para la Naturaleza Canadá), y una filial del World Wide Fund for Nature (Fondo Mundial Amplio para la Naturaleza). Una muestra representativa de 14 organizaciones nacionales se presenta en la tabla 1.

\section{Tácticas}

Los grupos ambientalistas emplean una amplia variedad de tácticas para influir en las actitudes de los canadienses, en las prácticas empresariales y en las acciones gubernamentales. Para fines analíticos, resulta útil dividir las actividades de los grupos ambientalistas entre aquellas que tratan de incidir en el comportamiento general de la sociedad y las que buscan influir en la política ambiental. La tabla 1 proporciona ejemplos sobre los tipos de tácticas y la forma en que la comunidad ambientalista influye en el debate canadiense. La mayoría de los grupos ambientalistasemplean estrategias que utilizan tácticas combinadas.

Los grupos ambientalistas usan las siguientes tácticas indirectas para influenciar los procesos de políticas públicas:

${ }^{5}$ Pollution Probe (Investigación sobre Contaminación), Energy Probe (Investigación sobre Energia) y Rawson Academy of Aquatic Science (Academia Rawson de Ciencias Acuáticas), entre otros. 
1) Intermediación: proporcionan la organización y los medios para el activismo de los ciudadanos y articulan una amplia variedad de opiniones y demandas. ${ }^{6}$

2) La conciencia de la sociedad: fortalecen la lealtad de los ciudadanos canadienses con los valores fundamentales, por medio de la crítica a las prácticas adoptadas por corporaciones, gobiernos, sindicatos, iglesias y demás.?

3) Relación con los medios de comunicación: transmiten el mensaje de grupos que carecen del presupuesto necesario para financiar compañas publicitarias.'

4) Construcción de redes sociales: funcionan como un mecanismo de apoyo para grupos pequeños y como un medio político poderoso para los grupos organizados.'

5) Apoyo internacional: crean redes de oposición para detener proyectos específicos ${ }^{10}$ o para participar en foros mundiales. ${ }^{11}$

6) Adopción de posiciones extremas: atraen la simpatía y la indignación del público. ${ }^{12}$

Los grupos ambientalistas usan las siguientes tácticas directas con el mismo propósito:

${ }^{6}$ Movilizaciones ambientalistas exitosas o no, incluyen al Valle Mackenzie, la Bahía James, el río Oldman y la Campaña del río Rouge.

' Por ejemplo, gmpos que proponen valores y actitudes alternativos para el reciclaje, la descarga de desechos tóxicos, el uso de animales para la investigación y el consumo de energía.

- Tal es el caso de David Suzuki, columnista comprometido y conductor del programa The Nature of Things" (La Naturaleza de las Cosas), de la CBC, quien dedica su espacio para criticar prácticas industriales y políticas gubernamentales.

' La Canadian Environmental Network (Red Ambiental Canadiense) funciona como un secretariado que facilita los vínculos entre los gmpos ambientalistas y otras organizaciones interesadas, en todo el país.

${ }^{10}$ Grupos ambientalistascanadienses, en colaboración con los grupos europeos, lograron que el Parlamento Europeo restringiera la importación de productos de cachorros de foca harpa canadiense.

${ }^{11}$ Participación internacional en la preparaciónde la Conferencia de las Naciones Unidas sobre el Ambiente y el Desarrollo (UNCED por sus siglas en inglés), realizada en Brasil, en 1992.

12 Activistas de Earth First! se encadenan a máquinas taladoras y practican el sabotaje ecológico en los bosques, facilitando el trabajo a grupos que no emplean esas tácticas pan negociar con los gobiernos y las compañías sobre los mismos temas.

1) Participación en consultas: ejercen presión sobre los gobiernos cuando se dan cambios en la legislación, las políticas, la regulación o los programas. ${ }^{13}$

2) Nombramientos en consejos asesores, mesas redondas, grupos de trabajo gubernamentales y en algunas compañías: expresan las perspectivas ambientalistas."

3) Investigación científica realizada por grupos ambientalistas: actúan como un sistema de alerta o sirven de base para proyectos mayores. ${ }^{15}$

4) Programas contratados con los gobiernos: apoyan la participación ambientalista significativa y equilibrada. ${ }^{16}$

5) Investigación para el desarrollo de políticas: asesoran a las instituciones gubernamentales y multilaterales en sus

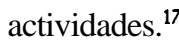

6) Trabajo de abogacía y cabildeo directo a gobiernos: defienden posiciones en proyectos y políticas, y promueven alternativas."

7) Crítica y apoyo: usan tácticas de protesta, ataque, procedimientos judiciales, monitoreo; y apoyo a políticos, programas o leyes cuestionadas por la industria, por otra

${ }^{13}$ Un ejemplo en el que la consulta pública ha sido institucionalizada en el proceso de toma de decisiones gubernamentales, es la enmienda de 1988 a la National Parks Act (Ley de Parques Nacionales).

${ }^{14}$ Un buen ejemplo de esto fue el National Task Force on Environment and Economy (NTFEE) (Grupo de Trabajo Nacional sobre Medio Ambiente y Economía\}, que tuvo dos representantes de grupos ambientalistasen un total de $\mathbf{1 7}$ miembros.

${ }^{15}$ El Western Canada Wilderness Committee (WCWC) (Comité para la Naturaleza de Canadá Occidental) ha llevado a cabo la investigación más grande del mundo sobre bosques tropicales en el Valle Carmanah, en Columbii Británica.

${ }^{16}$ Uno de los ejemplos más conocidosfue la Canadian Coalition on Acid Rain (Coalición Canadiense sobre la Lluvia Ácida) que recibió fondos del Ministerio de Medio Ambiente de

${ }^{17}$ En 1989, una coalición de 28 gmpos publicó un documento consensado, The Greenprint for Canada: A Federal Agenda for Environment (Informe Ambiental de Canadá: Una Agenda for Canada: A Federal Agenda for Environment (Informe Ambiental de Canadá: Una Agenda
Federal del Medio Ambiente), que bosquejaba una agenda ambiental de política gubernamental.

${ }^{18}$ En relación con la nota anterior, el Comité del Greenprint (Informe Ambiental) se reunió con el Primer Ministro y el Ministro del Medio Ambiente en junio de 1989, para reunió con el Primer Ministro y el Ministro del Medio Ambiente en junio de 1989, para
abogar a favor de la creación de una estrategia ambiental general acorde con los lineamientos del Greenprint (Informe Ambiental). 
instancia gubernamental o aun por otros grupos ambientalistas. ${ }^{19}$

\section{Cooperacióny conflicto}

Esta visión general del movimiento ambieńtalista canadiense ha mostrado que no tiene una estructura monolítica filosófica ni organizativa. Las relaciones entre los grupos ambientalistas fluctúan constantemente. Eso refleja, en parte, la dinámica y el crecimiento caótico que el movimiento ha experimentado durante los últimos diez años. Los grupos ambientalistas entran en procesos de cooperación y conflicto crecientes, a la vez que algunos grupos se esfuerzan por lograr estabilidad financiera y madurez organizativa.

Algunas tácticas de los grupos más radicales no son del agrado de los grupos conservacionistas, y viceversa; no obstante, hay un reconocimiento creciente de que ambos tienen algo que aportar para la consecución de los objetivos ambientalistas. Por ejemplo, grupos radicales como Greenpeace y Earth First! y organizaciones activistas como Friends of the Earth y Energy Probe son necesarios porque critican fuertemente a los gobiernos y a las industrias que no han cumplido con los programas ambientales. Asimismo, son necesarios grupos ambientalistas como Pollution Probe y el Institute for Research and Public Policy (Instituto para la Investigación y las Políticas Públicas), dado que participan en foros de discusión y cuestionan al Ministerio de Medio Ambiente y a los demás ministerios(McInnes, 1989). La preocupación por tener comunidades urbanas limpias, reservas naturales y áreas verdes, refleja un sentimiento compartido por los grupos conservacionista ambientalista y ecologista. Aun las iniciativas que vinculan temas económicos y ambientales han ganado apoyo amplio a través de todo el espectro del movimiento.

La esperanza de una mayor convergencia en el movimierto ambientalista está contrarrestada por una comprensión realista de las fuerzas que tienden al conflicto. Siempre hay algunas diferencias de opinión en la comunidad ambientalista sobre acciones o estrategias específicas. Tal fue el caso acerca de si los grupos ambientalistas debían haberse rehusado a participar en negociaciones sobre el

19 Por ejemplo, la Canadian Wildlife Federation recurrió a las cortes para oponerse al proyecto del gasoducto del Valle Mackenzie en los años setenta, $y$ al proyecto de la presa Rafferty-Alameda en Saskatchewan en los años ochenta. cambio climático con el gobierno federal a principios de la década. Sin embargo, los dos puntos principales de divergencia giran alrededor de dos temas. Primero, la cercanía con la que se debe trabajar con los sectores corporativos, ya que el acceso a los fondos empresariales ayuda a nivelar la situación financiera de los grupos, pero existen la amenaza y el miedo constantes de que sean cooptados. El caso Loblaws-PollutionProbe es el ejemplo citado con más frecuencia. ${ }^{20}$ Segundo, el debate sobre la reforma o el cambio social que se da en el conservacionismo, liberalismo y las ideologías radicales o alternativas; por ejemplo, las divergencias sobre libre comercio entre los ambientalistas.

Existen puntos donde la convergencia es posible, al mismo tiempo que hay otros de intenso desacuerdo. El éxito del movimiento en el largo plazo se basa en parte en su habilidad para tolerar un amplio espectro de puntos de vista. Esto no es fácil en un movimiento que incluye tanto a radicales que pregonan el regreso a la naturaleza, como a cazadores por deporte.

\section{Abogacía ambiental canadiense}

En un sentido amplio, los grupos ambientales son organizaciones de abogacía social. Comparten características comunes con otras organizaciones en Canadá, como los movimientos en favor de la mujer, de los derechos humanos, de la paz y de los movimientos étnicos. En este artículo se define la abogacía social como una forma positiva de protesta llevada a cabo por un grupo o una red social definida (Harries-Jones, 1991). La abogacía social desafía los valores y creencias dominantes por medio de la protesta. Se provee de un conocimiento científico y cultural nuevo que promueve varias formas de compromiso político. La abogacía es un proceso comunicativo mayor en las democracias modernas por el que formas alternativas de conocimiento entran en la construcción de la sociedad. Los grupos ambientalistas son extraparlamentarios, mas no violentos; combinan actividades para elevar la conciencia y adquirir fuerza política con el propósito de cuestionar a las legislaturas parlamentarias en nombre del interés público.

${ }^{20}$ Pollution Probe decidió apoyar la campaña verde de Loblaws, una gran cadena de supermercados., 


\section{Organización y finanzas}

La abogacía ambiental en Canadá adopta tres formas. La primera y más importante es la abogacía legal, que tramita órdenes judiciales de las cortes o revisiones ambientales. La segunda es el cabildeo político de agencias provinciales, federales e internacionales; y la tercera es la abogacía ejercida a través de los medios de comunicación (Harries-Jones, 1993).

La abogacía legal es necesaria para los ambientalistas porque los contribuyentes comunes no pueden dar curso a acciones legales contra corporaciones grandes y poderosas. $\mathrm{La}$ acción individual contra la contaminación del aire y otros asuntos ambientales aún no está permitida. La Canadian Environmental Law Association (CELA) (Asociación Canadiense sobre Ley Ambiental) estableció el Environmental Defense Fund (Fondo para la Defensa Ambiental), que ayuda a las organizaciones de base a vencer las desventajas de su tamaño para librar disputas locales en las cortes. Su objetivo es sentar precedentes legales en los criterios de las revisiones ambientales para contribuir a que en el futuro haya una contabilidad estricta de la sustentabilidad en Canadá.

La responsabilidad de la política ambiental está dividida entre las jurisdicciones federal y las provinciales. Esta división se complica con las disputas entre los ministerios y los departamentos en Ottawa, que se resisten activamente a cualquier posibilidad de que el Ministerio de Medio Ambiente de Canadá se convierta en un superministerio que vigile la compatibilidad de las políticas gubernamentales. Los activistas pierden mucho tiempo en lograr que el gobierno haga algo. A menudo piensan que las obstrucciones a la acción ambiental no tienen relación con la falta de apoyo a sus iniciativas, sino que requieren un cambio significativo en el proceso de toma de decisiones de la burocracia gubernamental.

En años recientes, la Comisión Brundtland ha sido un referente para la actividad del conjunto de grupos ambientalistas en Canadá. El reporte de esta comisión reconoció el papel de los grupos ambientalistas y ciudadanos al impulsar y mantener la atención pública y política en los peligros ambientales y promover medidas prácticas para manejarlos. (Brundtland, 1987). La National Round Table on Environment and Economy (Mesa Redonda sobre Medio Ambiente y Economía), así como las Provincial Round Tables (Mesas Redondas Provinciales) fueron establecidas desde 1988 para cumplir con el compromiso de Canadá con el Reporte Brundtland. La mesa redonda se basa en un principio de asociación para el desarrollo sustentable. La asociación en este contexto significa un procedimiento triple de toma de decisiones que involucra a grupos ambientalistas, gobiernos y empresas. La adopción gubernamental del desarrollo sustentable y del principio de asociación ha sido un recurso ambivalente para la abogacía ambiental. Las deliberaciones de la mesa redonda han sido extremadamente lentas a los ojos de los ambientalistas; tanto, que la participación es sólo un acto retórico. Muchos activistas han quedado exhaustos por el proceso de dilación y carencia de respuestas de los ministerios gubernamentales. Por esta razón los grupos ambientalistas funcionan a menudo en oposición a las políticas gubernamentales, en vez de asociarse con ellas.

Su estrategia de oposición se modifica por el hecho de que gran parte de la abogacía en Canadá asume la forma de abogacía cooptada (Etzioni-Halevy, 1990). Está cooptada en el sentido de que la mayoría de las organizaciones de abogacía carecen de una base de miembros lo suficientemente grande como para ser autónomas, por lo cual tienen que depender directamente del financiamiento gubernamental. Otros obtienen ayuda financiera mediante contratos de consultoría otorgados por el gobierno. Aun en esos casos, como el de Pollution Probe, no pueden confiar en un ingreso anual seguro, sobre todo en tiempos de recesión económica. Esto significa que la mayoría de los grupos de abogacía dedican la mayor parte de su tiempo a combatir crisis financieras recurrentes. Greenpeace es una excepción; después de los años de carestía de principios de los ochenta, puede sostenerse completamente con las donaciones de la gente de base.

Todos los grupos de abogacía ambiental, incluyendo a Greenpeace, sufren de una gran movilidad de personal. Greenpeace ha controlado este flujo de personal separando a su consejo ejecutivo de sus comités cotidianos de recolección de fondos, telefonía y acción local. Muchas otras organizaciones de abogacía tienen recursos escasos como para adoptar esta solución. Sus ejecutivos son responsables de todos los aspectos de movilización y constantemente tienen que escoger entre varias actividades: investigación o recolección de fondos, educación pública por medio de publicaciones u oposición política, organización de actividades comunitarias o construcción de redes con otras organizaciones ambientalistas. El eterno problema es estar por encima de las demandas principales de sobrevivencia organizacional para mantener sus posiciones como cabilderos efectivos.

La escasez de fondos, el exceso de compromisos, y la tentación de mejores salarios y condiciones, son una combinación 
poderosa que propicia cambios constantes en su personal. Como es de esperarse, esta situación tiende a reducir al conjunto de organizaciones de abogacía a actores claves. Entre veinticinco y cincuenta actores sociales mantienen a las organizaciones cooptadas unidas.

\section{Orientaciones políticas de la abogacía ambientalista}

Los ambientalistas canadienses generalmente no tienen problema en definir contra quién están, pero sí en presentar una plataforma unificada sobre lo que buscan. Esto se debe en parte a que sus miembros son básicamente de clase media y provienen de posiciones políticas que van desde la social demócrata, marxista y anarquista, hasta la centro-derechista. Por eso tienen perspectivas muy diferentes sobre qué posiciones activistas asumir. Sus opositores más comunes son los neoconservadores, identificados en el ámbito nacional con el Partido Conservador y sus consejos de apoyo con intereses empresariales; con el Partido de Reforma y la Nationalist Citizen Coalition (Coalición Nacionalista de Ciudadanos), un grupo de empresarios populistas; y con una variedad amplia de think tanks (consultores) como el C. D. Howe Institute (Instituto C. D. Howe). Hay tres orientaciones políticas principales identificadas entre los miembros de las organizaciones ambientalistas: abogacía conservacionista, abogacía radical y abogacía indígena-activista.

1) La abogacía conservacionista está integrada principalmente por reformistas pragmáticos. Poseen una serie de conexiones comunes pero laxas por medio de la Canadian Environmental Network, a la que están vinculados electrónicamente mediante de la red WEB donde discuten los planes conjuntos. World Wildlife Fund Canada y el Conservation Council of Ontario (Consejo para la Conservación en Ontario) son ejemplos de reformistas pragmáticos. El nivel de profesionalización del WWFC permite compararlo con una firma empresarial exitosa. Tienen un fuerte sentido del poder del statu quo, y están dispuestos a adoptar una política de adulación a empresas, si ello los lleva a una acción positiva en cuestiones ambientales. ${ }^{21}$

${ }^{21}$ Un miembro anónimo de la WrWFC reconoció que algunos de los contaminadores mayores en Canadá son inversionistas importantes en el Wildlife Toxicology Fund (Fondo Toxicológico para la Naturaleza), establecido por la WWFFC.
En ocasiones, las tensiones del papeleo, la inactividad gubernamental y el encubrimiento pragmático de la industria, afectan la operación de la organización. El caso más notable fue el de Pollution Probe cuando su director, Collin Isaacs, decidió apoyar la campaña de consumo verde de Loblaws. Sus miembrosinsistieron en que renunciara, después de lo cual Pollution Probe sufrió una reorganización total. El nuevo consejo de directores modificó el rumbo. Aun cuando continúa manteniendo una función política de investigación, presta mayor atención al aspecto público de la divulęación de información.

El Conservation Council of Ontario es una organización paraguas que comprende a 31 grupos. A diferencia de otros reformistas pragmáticos, opera con muy poco contacto e incluso interés en los ciudadanos comunes. Representa a organizaciones profesionales dedicadas a la planeación ambiental. Los miembros del Consejo son básicamente representantes del statu quo que buscan reducir la influencia de los grupos ambientalistas de base haciendo propuestas al proceso de toma de decisiones centralizado, por medio de los ministros.

Las universidades en Canadá son una importante fuente de recursos intelectuales para los movimientos, y juegan un papel más prominente en la investigación de políticas y la abogacía social que en los Estados Unidos, donde las actividades de los grupos ambientalistassonfuertemente apoyadas por cabilderosprofesionales (Harries-Jones, 1991). La universidad ha representado un papel importante apoyando algunas organizaciones de abogacía tales como Pollution Probe, Probe International (Investigación Internacional) y la Coalition Against Acid Rain (Coalición contra la Lluvia Acida). Sus vínculos con el movimiento ambientalista de base han sido moderados debido a que las donaciones favorecen la asociación entre universidades y empresas para la acción ambiental.

2) La abogacía radical está representada por Greenpeace Canada. Es radical en el sentido de que constantemente desafía la relación establecida entre el gobierno y las empresas, demandando que éste reconozca la necesidad del involucramiento ciudadano. La demanda de participación ciudadana es general entre los radicales y 
conservacionistas mediante la Canadian Environmental Network ${ }^{22}$ Los radicales demandan que el gobierno se comprometa a apoyar públicamente a los grupos ambientalistas, establezca comités para supervisar el impacto de las políticas existentes y los acuerdos en materia ambiental, y coloque en la mira a las compañías individuales o los ministros que rehúsen obrar de acuerdo con las decisiones relacionadas con el ambiente.

Por un tiempo, Greenpeace estuvo divididoentre la abogacía radical y el activismo militante. Paul Watson, uno de sus fundadores, organizó una campaña para prohibir la navegación en las aguas costeras de Newfoundland. La campaña de 1993 fue planeada conjuntamente con organizaciones de derechos animales. A pesar de que fue un triunfo de Greenpeace en la Comunidad Europea, la campaña fue un desastre para sus miembros en Canadá y ocasionó que Watson renunciara algunos meses después. Ante esto, fundó la Sea Shepherd Conservation Society (Sociedad para la Conservación del Mar), que entre otras cosas, se opuso vehementemente a la vivisección (Manes, 1990). Después, Watson se mudó a los Estados Unidos, donde organizó Earth First!, un grupo de acción política que ha asumido la responsabilidad de varios actos de sabotaje ecológico, en nombre de la abogacía ecológica. ${ }^{23}$

Casi desde el principio, Greenpeace organizó prácticas simbólicas y vinculó los medios de comunicación con sus objetivos organizacionales. Su meta principal es dar testimonio de una variedad de situaciones insostenibles. Las señala de la manera más dramática para hacer visibles los efectos de la degradación ecológica, que de otra forma quedarían ocultos. Greenpeace ha pasado de los ecodramas reales a la simulación de ecodramas: sus miembros dejaron de hacer viajes reales contra barcos armados para escalar torres y puentes desplegando carteles de protesta. Esta segunda estrategia es muy efectiva porque presenta los asuntos ambientales complejos de un modo amigable. Los ambientalistas han aprendido de los éxitos de Greenpeace al respecto.

${ }^{n}$ La Canadian Environmental Network ha protestado porque los gobiernos canadiense consultan a puerta cerrada con los intereses poderosos antes de tomar cualquier decisión importante. En teoría, los canadienses viven en una democracia; pero en la práctica, la concentración del poder económico y político en la sociedad canadiense limita la capacidad ciudadana para participar en su propio gobierno, incluyendo la protección del ambiente.

${ }^{23}$ Earth First! opera fundamentalmente en los Estados Unidos y en Columbia Británica, y tiene algún apoyo en universidades de Ontario.
David Suzuki es el intelectual más conocido del movimiento, por su influencia en columnas periodísticas y en la televisión. Ha sido un activista por la paz y un líder del pensamiento ecologista. Su serie de televisión, “The Nature of Things”, ha apoyado casos como el de los indios Cree en su lucha contra el gran proyecta hidroeléctrico conocido como "James Bay Two" (BahíaJames Dos). El protagonismo de David Suzuki tiene que ver con el cambio de la práctica cognoscitiva por la práctica simbólica, como la forma predominante de conocimiento en Ontario. Sus intervenciones en los medios, especialmente en la televisión, son cruciales porque median el espacio político canadiense y contribuyen fuertemente a la formación de la gestalt del movimiento ambientalista.

3) La abogacía indígena-activista vincula a los ambientalistas con las demandas territoriales de First Nations (Primeras Naciones). Este es un rasgo especial del movimiento ambientalista en Canadá. En Columbia Británica y en Quebec, por ejemplo, la relación entre los dos ha alcanzado algunos éxitos. En el caso de la disputa de South Moreby en Columbia Británica, las relaciones entre la industria maderera y el gobierno provincial se rompieron irremediablemente en mayo de 1990.

En Ontario la acción conjunta es vacilante y generalmente pobre, debido a la ausencia de una política ambientalista unificada en First Nations, así como a los conflictos de personalidad y al choque de aspiraciones culturales entre los ambientalistas y los líderes indios. Esto fue evidente en la protesta de la Temagami Wilderness Society (TWS) (Sociedad Temagami para la Naturaleza). El jefe Gary Potts, de Tema-A waugame, organizó dos bloqueos independientes bajo el argumento de que la TWS se había preocupado únicamente por la protección de los árboles en territorio Crown, mientras que su propio grupo quería la protección de todos sus recursos naturales.

Coexistencia en el espectro ambientalista

No es raro que los ambientalistas tengan membresía en varios grupos y que los activistas ambientalistas no pertenezcan exclusivamente a una organización. Los directivos principales de los grupos ambientalistas actuales han sido directores de otros grupos, han ayudado a conseguir fondos, han realizado actividades educativas y de toma de conciencia de otros grupos, o incluso fueron 
fundadores de otras organizaciones ambientalistas. Los activistas veteranos generalmente usan varios "sombreros" en el movimiento. Hay un esfuerzo consciente -que en ocasiones no soporta la fricción de personalidades - para construir relaciones que celebren los éxitos de otros, y que ofrezcan información conjunta al público.

Una observación sorprendente sobre el movimiento ambientalista en Canadá y en los Estados Unidos es que se encuentran ambientalistas serios a todo lo largo del espectro político, de izquierda a derecha (Paehlke, 1989). No obstante, haciendo a un lado las orientaciones políticas discordantes, varios grupos de la abogacía ambiental han evitado la competencia por los recursos, y creado una red de ambientalistas que vincula a los grupos más grandes con los grupos pequeños que promueven asuntos ambientales locales.

\section{Movimiento social canadiense frente al libre comercio ${ }^{24}$}

El movimiento ambientalista canadiense se opuso al ALCEUC y al TLCAN, con la excepción de Pollution Probe. Con este propósito, participó en la organización de coaliciones por medio de sectores y en las conexiones transnacionales con sus contrapartes en los Estados Unidos y México. La Pro-Canada Network (PCN) (Red Pro-Canadá), que se transformó en la Action Canada Network (ACN) (Red Canadiense de Acción) en 1991, fue un actor líder en este proceso. Es una coalición de organizaciones laborales, ambientalistas, culturales, religiosas, contra la pobreza, de mujeres y profesionistas. Para entender mejor la naturaleza y la dinámica de la ACN frente a temas ambientales, es necesario hacer una breve revisión del

${ }^{24}$ Esta sección del artículo está basada en entrevistas con: Craig Boljkovac, miembro del consejo, Internation Affairs Caucus, Canadian Environmental Law Association (Crupo de Asuntos Internacionales, Asociación Canadiense sobre Ley Ambiental), Ottawa, Canadá, Asuntos Internacionales, Asociación Canadiense sobre Ley Ambiental), Ottawa, Canadá, 27/07/96; Cathy Cameron, enlace internacional, Canadian Environmental Network, Ottawa, Canadá, 26/07/96; Bruce Campbell, director general, Canadian Center for Policy Alternatives (Centro Canadiense de Políticas Alternativas), Ottawa, Canadá, 26/07/96; Tony Clarke, ex director general, Action Canada Network, Ottawa, Canadá, 27/07/96; Elizabeth Everhartus, asistente del director general, Poliution Probe, Toronto, Canadá, 30/07/96; Janine Ferretti, directora, Comisión de Cooperación Ambiental de América del Norte (CCA), Montreal, Canadá, 24/07/96 y ex directora general, Pollution Probe; Joanne Polky, coordinadora administrativa y de membresía, The Council of Canadians (Consejo de Canadienses), Ottawa, Canadá, 26/07/96; Dana Silk, jefe del Programa del Protocolo de Montreal, Friends of the Earth Canada (Amigos de la Tierra Canadá), Montreal, Canadá, 16/07/96; y Ken Traynor, coordinador de relaciones, Canadian Environmental Law Association, Toronto, Canadá, 29/07/96. contexto y de las condiciones de la formación de coaliciones en Canadá a mediados de los años ochenta.

\section{Contexto y condiciones de la formación de coaliciones}

Existen varios factores externos que explican el incremento de las coaliciones en Canadá durante los años ochenta. El primero fue la crisis en el Partido Liberal y su posición como partido predominante del gobierno en el siglo XX. Sin una reforma impositiva importante durante los años sesenta y setenta, el gobierno liberal enfrentó limitaciones fiscales en el mantenimiento del federalismo canadiense y su compromiso con el acceso universal a los programas sociales. Segundo, formas nuevas de organización entre los empresarios surgieron en 1976. El Business Council on National Issues (BCNI) (Consejo Empresarial de Asuntos Nacionales) se organizó reuniendo a las compañías más grandes en Canadá. Tercero, la Canadian Conference of Catholic Bishops (Conferencia Canadiense de Obispos Católicos) hizo una declaración trascendente el $1^{\circ}$ de enero de 1983. Dio a conocer el documento "Ethical Reflections on the Economic Crisis" ("Reflexiones éticas sobre la crisis económica"), que tuvo un efecto importante en Canadá. Señaló que la crisis afectó a los trabajadores y a las personas sin ingresos, demandó una reforma de los impuestos, y se pronunció en favor de la postura desarrollada en el GATT-fly - que posteriormente se convirtió en la Ecumenical Coalition For Economic Justice (Coalición Ecuménica para la Justicia Económica). Muchas otras iglesias apoyaron el documento o presentaron declaraciones propias sobre la situación económica.

La respuesta de formación de coaliciones ante el llamado de justicia social de las iglesias fue amplio. Se dio el renacimiento de una posición social en el sindicalismo canadiense, que se opuso a las restricciones salariales federales y a los recortes provinciales "neoconservadores" en los servicios públicos. Esto llevó a considerar la necesidad de nuevos aliados, ya que la alianza del New Democratic Party (Nuevo Partido Demócrata) con movimientos organizados laborales, sociales y de combate contra la pobreza, se debilitaría cuando este partido se encontrara fuera del poder. El diálogo y el debate generado por la declaración de los obispos comprometió a otros grupos que estaban alcanzando la madurez organizacional: los movimientos ambientalista, de la mujer, y por la paz, así como el liderazgo de las naciones indígenas. 
La organización del movimiento creció con la tendencia conservadora de las políticas gubernamentales provinciales a principios de los ochenta, y con la elección de Mulroney. Esto llevó a una nueva experiencia de formación de coaliciones de justicia social en los ámbitos local o provincial. En 1983, uno de los esfuerzos más importantes ocurrió en Columbia Británica con Solidaridad, que intentó reunir a grupos laborales, indígenas, ambientalistas, de mujeres, magisteriales, de discapacitados, y de combate a la pobreza, con el fin de enfrentar las políticas de recorte social y "antilaborales ${ }^{\mathrm{n}}$ del área de Crédito Social del gobierno provincial. El gran esfuerzo organizativo provincial estuvo a punto de culminar en una huelga general cuando el líder del sindicato más grande de trabajadores de la madera y el gobierno negociaron y llegaron a un acuerdo. Esto condujo a un periodo de recriminaciones y evaluación de las dificultades para organizar coaliciones entre agrupaciones laborales y no laborales.

Mientras que a los movimientos sociales en Columbia Británica les tomó tiempo recuperarse, se formaron alianzas en otras provincias. La Coalition for Equality (Coalición para la Igualdad)en Newfoundland reunió a grupos religiosos, de combate a la pobreza, de mujeres, y laborales, en el contexto de un conflicto industrial en la planta empacadora de Gainer's Meat (Carne de Gainer) en Alberta. En 1985, en Quebec, el Conseil des Syndicats Nationaux (Consejo de Sindicatos Nacionales) formó Solidarité Populaire Quebec (Solidaridad Popular de Quebec) como una respuesta a los recortes de los programas sociales del primer presupuesto federal conservador. En 1987, la Saskatchewan Coalition for Social Justice (Coalición Saskatchewan para la Justicia Social) se formó en respuesta al presupuesto conservador de la provincia en marzo de 1987.

Quizás el esfuerzo más significativo fue la formación de la Coalition Against Free Trade (Coalición contra el Libre Comercio), en Ontario, en 1985, con los líderes del National Action Committee on Status of Women (Comité de Acción Nacional sobre el Status de las Mujeres), el Writer's Union (Sindicato de Escritores), la pequeña y autónoma Confederation of Canadian Unions (Confederación de Sindicatos Canadienses), y los grupos religiosos. Dicha organización involucró la participación efectiva de un gran número de sindicatos mayores afiliados al Canadian Labour Congress (Congreso Labora Canadiense) y a la Ontario Federation of Labour (Federación Laboral de Ontario). Al aproximarse las elecciones de 1988, la coalición tuvo acceso a consejeros cercanos al líder liberal y prime ministro, John Turner, y organizó dos encuentros con el primer ministro liberal provincial David Peterson.

Esta serie de factores crearon una atmósfera alentadora para que grupos nacionales religiosos, de mujeres, arnbientalistas, y laborales, iniciaran un diálogo sustantivoen 1986 y 1987. El proceso no estuvo exento de dificultades; tuvieron que superar susceptibilidades y diferencias políticas. Algunos avances en la forma y las prácticas organizativas fueron importantes, particularmente entre los movimientos ambientalistas, de mujeres, y las organizaciones laborales más tradicionales. La debilidad de la izquierda redujo el temor del liderazgo laboral no comunista frente a grupos y movimientos externos, así como ante las complicaciones para organizar coaliciones multisectoriales. A pesar de los reveses y la escasez crónica de recursos, la Coalición Against Free Trade y muchas otras organizaciones se unieron en la Pro-Canada Network en 1987.

Aun cuando mucho de lo que se ha señalado arriba involucró y afectó a los movimientos sociales en Quebec, la dinámica en la sociedad de Quebec resulta intensa, y la orientación es lo suficientemente diferente como para ser estudiada en sí misma. Por tal motivo, las coaliciones ofrecieron un taller en el que activistas canadienses de habla inglesa, activistas quebequenses, y líderes de movimientos, podrían dialogar y trabajar en posiciones comunes opuestas a la agenda del BCNI y el gobierno federal. Este taller fue una experiencia única y nueva en la sociedad canadiense. Sin embargo, la alianza en sí misma era asimétrica. Los intentos por llegar a una forma organizativa y un estilo de liderazgo adecuados no fueron fáciles. Los alcances del acuerdo sobre objetivos estratégicos y tácticas organizativas no fueron del todo claros para las organizaciones locales.

\section{Action Canada Network}

La Pro-Canada Network cambió su nombre a Action Canada Network (ACN) en 1991. Su membresía estaba integrada por organizaciones laborales del Canadian Labour Congress y otras organizaciones de mujeres, estudiantiles, rurales, de la tercera edad, de salud pública, ambientalistas y religiosas. Además de las organizaciones laborales, los grupos profesionales jugaron un papel activo, en particular las organizaciones magisteriales nacionales y regionales, así como el sindicato de enfermeras. Entre los grupos no 
laborales y profesionales, quizá los más significativos fueron la Canadian Conference of Catholic Bishops - con mayor presencia en el periodo 1986-88-, la Ecumenical Coalition for Economic Justice - anteriormente GATT-fly-, el Inter-Church Committee on Human Rights in Latin America (Comité Inter-Iglesia sobre los Derechos Humanos en América Latina), y el Jesuit Center for Social Faith and Justice (Centro Jesuita para la Fe y Justicia Social). La posición pública y la base más dinámica fue aquella del movimiento de mujeres y el liderazgo público asumido por el National Action Committee (Comité de Acción Nacional).

La ACN contaba con una gran cantidad de grupos del movimiento ambientalista canadiense, pero no eran todos. La Canadian Environmental Law Association desempeño un papel protagónico; contaba con investigadores sobre el agua, los bosques y otros recursos. La Canadian Environmental Network fue muy Útil por su gran capacidad de comunicación y coordinación.

Hubo otras organizaciones de base involucradas, especialmente de la tercera edad, redes de combate a la pobreza, de estudiantes, de trabajadores del sector cultural, y la gran organización nacionalista Council of Canadians (Consejo de Canadienses). Este consejo proveyó un liderazgo político significativo y visible, además de vínculos con una variedad de gente que no podía identificarse con el movimiento laboral, por ejemplo. Las coaliciones provinciales estaban integradas a la organización nacional y tuvieron su propia membresía. Algunas de las coaliciones, incluyendo las de Alberta, Ontario y Quebec, desarrollaron redes de coaliciones regionales y locales en sus provincias.

Las coaliciones se referían a sus bases como el sector social, movimientos laborales y comunitarios, movimientos sociales o populares. Dada la participación predominante de organizaciones de base amplia en la ACN, parece más adecuado utilizar el término de movimientos sociales en lugar del de organizaciones no gubernamentales, porque éste tiene un significado más restringido en el contexto canadiense.

La mayor parte de los grupos sociales no tenían una orientación internacional. El Canadian Council for Internationa Cooperation (Consejo Canadiense para la Cooperación Internacional) -que abarcaba más de 150 organizaciones internacionales grandes y pequeñas - tuvo dificultades considerables para establecer una posición y una línea de acción e investigación con relación al comercio. Los temas de comercio y desarrollo eran vistos por algunos miembros como inadecuados, demasiado políticos y controversiales. Incluso las organizaciones con una fuerte retórica de alianzas con el sector social tuvieron dificultades en establecer una posición. A excepción de la Canadian Environmental Law Association y del Latin American Working Group (Grupo de Trabajo Latinoamericano), ningún grupo estuvo directamente involucrado en el debate comercial durante el periodo 1986-1988.

La experiencia de las fuerzas sociales canadienses opositoras al ALCEUC, en relación con sus contrapartes en los Estados Unidos, fue abismal durante las negociaciones. Una coalición sindical (religiosa y de mujeres) visitó Washington en el verano de 1987, y encontró una ignorancia general sobre el proceso canadiense y una falta de interés entre muchos de los grupos estadounidenses. Los canadienses opositores al ALCEUC desafiaban los valores principales del libre comercio de la administración Reagan y la supremacía del Congreso. Mediante entrevistas con los cabildos de empresas y los investigadores del congreso, lograron entender la agencia estadounidense, tuvieron acceso al flujo de información en Washington, recibieron cobertura de la prensa, y establecieron algunos contactos que posteriormente fueron de utilidad cuando los estadounidenses se enfrentaron con las negociaciones del TLCAN.

En el contexto del TLCAN, se puede decir que los canadienses hallaron a los mexicanos en su camino hacia América Central. El Latin American Working Group tenía relaciones amistosas con organizaciones solidarias mexicanas desde principios de los años setenta, pero la cantidad y la solidez de las conexiones se multiplicó en los años ochenta como respuesta a la guerra y a la tragedia en América Central. La presencia de ayuda, de representantes políticos centroamericanos y de las grandes comunidades de refugiados en México, hizo que la presencia de organizaciones canadienses religiosas y de agencias de ayuda fuera más frecuente en México. Ambas entraron en contacto con sus contrapartes mexicanas y adquirieron interés periódico en la política exterior y de refugiados mexicana.

En 1988, en el periodo preelectoral en Canadá, el Latin American Working Group, el GATT-fly, y la B. C. Trade Union Group (Grupo Sindical de B. C.) organizaron un viaje para conocer la situación laboral en las maquiladoras. El resultado fue un proyecto de análisis y monitoreo llamado Common Frontiers (Fronteras Comunes). Al año siguiente, un grupo de mexicanos interesados en el seguimiento del tema y en continuar el diálogo con los canadienses, estableció un pequeño proyecto, "Fronteras Comunes $^{\mathrm{n}}$, que obtuvo fondos canadienses e internacionales 
limitados. Hubo intercambio y visitas entre ambas organizaciones, a pesar de no estar vinculadas formalmente.

Con el anuncio de las negociaciones de libre comercio entre los Estados Unidos y México a mediados de 1990, así como con la rápida inclusión de Canadá y el subsecuente lanzamiento de la "Iniciativa de las Américas", comenzó una nueva etapa de actividades. Tres eventos en 1990 marcaron un cambio significativo en la colaboración mexicano-canadiense sobre asuntos comerciales. Los días 7 y 8 de diciembre, Cuauhtémoc Cárdenas, invitado por el New Democratic Party y el crítico de comercio Dave Barren, visitó Columbia Británica, habló frente a la B. C. Federation of Labour (Federación Laboral de B. C.) y se reunió con los líderes de Action Canada (Canadá Acción) y Common Frontiers.

Poco después, el Partido Acción Nacional (PAN), de México, apoyó un coloquio sobre el libre comercio e invitó a veinte canadienses, diez a favor y diez en contra, a discutir sus experiencias frente al ALCEUC. Unos días más tarde, treinta canadienses y más de sesenta mexicanos representantes de sindicatos, de mujeres, de ambientalistas y de indígenas, se reunieron en las oficinas del Frente Auténtico del Trabajo, en el primer Encuentro de las Organizaciones Sociales frente al Libre Comercio entre México y Canadá, organizado por Fronteras Comunes y varios grupos más. Debatieron sobre los problemas del ALCEUC y sus similitudes con la integración "silenciosa" de México. Los intercambios periódicos entre coaliciones y grupos canadienses y mexicanos aumentaron, y en 1991 se creó la Red Mexicana de Acción frente al Libre Comercio (RMALC) como contraparte de la Action Canada Network.

Representantes de la coalición canadiense se reunieron con sus homólogos estadounidenses y mexicanos a finales de octubre de 1990 en Washington, y consideraron la posibilidad de una colaboración trilateral en el futuro. El primer caso fueron las relaciones entre las coaliciones de México y Canadá, y las más activas en los Estados Unidos. Se analizaron diferentes tipos de actividad: intercambio de información y discusión sobre la estrategia política amplia, análisis y definición de intereses comunes, e iniciativas tácticas. Estos procesos se llevaron a cabo por medio de la conversación trinacional entre las coaliciones, con el apoyo del personal de Common Frontiers y U.S.-Mexico Dialogs (Diálogos México-Estados Unidos), quienes y a habían construido redes de contactos e información. Asimismo, hubo procesos sectoriales que ganaron un ímpetu propio, incluyendo el intercambio agro- ambiental en una reunión de especialistas en noviembre de 1991 en la Ciudad de México, y colaboraciones posteriores.

La crítica de la Action Canada Network al TLCAN estuvo estrechamente relacionada con la crítica original al ALCEUC y la experiencia canadiense posterior. El Canadian Center for Policy Alternatives señaló que “ [...] en el análisis del TLCAN, debía tenerse en mente que el asunto principal para los canadienses seguía siendo el ALCEUC [...], y que los principios y arquitectura básicos del TLCAN eran los mismos que los del ALCEUC ${ }^{n}$ (Campbell, 1992). En resumen, las principales preocupaciones externadas por los equipos de análisis de la coalición en noviembre de 1992, fueron que el TLCAN: 1) protege a los Estados Unidos de posibles daños si fallan las negociaciones del GATT; 2) tiene más poder efectivo que el ALCEUC en las provincias canadienses; 3) amplía considerablemente la cobertura del sector de los servicios del ALCEUC; 4) protege los llamados "derechos de propiedad intelectual" de Ias corporaciones transnacionales; 5) restringe aún más la regulación de la inversión de los gobiernos canadienses; 6) socava la capacidad canadiense para desafiar las arbitrariedades de las leyes comerciales estadounidenses; 万 tiende a la supremacía creciente de sus regulaciones y tiene implicaciones importantes para las economías menos desarrolladas y 8) debilita la capacidad de los grupos de abogacía para mantener altos índices de salud y seguridad, de normas ambientales y laborales. La administración Clinton reabrió estos temas al escrutinio y debate público, al comprometerse a negociar los acuerdos paralelos.

\section{El movimiento ambientalistaen Canadá: los casos del ALCEUC y} el TLCAN

El movimiento ambientalista canadiense siempre ha trabajado en coaliciones, al menos en su interior, y las negociaciones del ALCEUC y el TLCAN no fueron la excepción. La mayoría de los ambientalistas canadienses aumentaron paulatinamente su preocupación por los posibles impactos ambientales del ALCEUC. Se opusieron a una declaración del ministro federal de Comercio Internacional, John Crosbie, en el verano de 1987:

El tratado de libre comercio es un acuerdo comercial entre los dos socios comerciales más grandes del mundo. No es un acuerdo ambiental. El ambiente, no es por tanto, materia de 
Esta declaración contradijo el compromiso del gobierno canadiense con el informe de la World Commission on Environment and Development (Comisión Mundial sobre Medio Ambiente y Desarrollo) (Bruntland, 1987) para integrar la toma de decisiones en materias económica y ambiental que produjera cambios sustantivos en las políticas. Los ambientalistas consideraron este hecho como la evidencia de que se requeriría una fuerte presión para lograr que los gobiernos mantuvieran su nuevo compromiso con el desarrollo sustentable.

Poco después de la publicación del texto final, la Canadian Environmental Law Association produjo un análisis del ALCEUC titulado "Selling Canada's Environment Short: The Environmental Case Against the Trade Deal" ("Vendiendo barato el medio ambiente de Canadá: El caso ambiental contra el Acuerdo Comercial"). El documento describiólas implicaciones perjudiciales del ALCEUC, y para agosto de 1988, más de 90 grupos ambientalistas de todas las regiones de Canadá habían suscrito el análisis de CELA. La coalición de los grupos ambientales lanzó una campaña contra el ALCEUC sin precedentes por su tamaño y alcances. Los logros alcanzados por los ambientalistas canadienses ayudaron a estimular un debate internacional serio sobre las consecuencias ambientales de la política comercial. Este debate abarcó al TLCAN, a la Ronda Uruguay del GATT, a la United Nations Conference on Environment and Development (Conferencia de las Naciones Unidas sobre Medio Ambiente y Desarrollo), y al OECD Working Group on Trade and Development (Grupo de Trabajo de la OECD sobre Comercio y Desarrollo).

\section{Principales organizaciones ambientalistas en el debate comercial}

Las principales organizaciones ambientalistas canadienses en el debate comercial durante las negociaciones del TLCAN fueron Pollution Probe y la CELA. Ambas son miembros de la Canadian Environmental Network, que es una organización no gubernamental y no lucrativa que incluye a más de 2,000 grupos ambientalistas en el país. Debido a que su papel es facilitar la comunicación y la interacción entre grupos, ha mantenido neutralidad sobre los temas en debate. La preocupación sobre las implicaciones ambientales

nocivas del ALCEUC fue aumentando en las reuniones del Caucus de la CEN y abarcó un rango amplio de temas, incluyendo los estudios sobre impacto ambiental, bosques, agua y pesticidas. Su International Affairs Caucus fue creado en 1990, y dentro de él, el Alternative Economics and Trade Working Group (Grupo de Trabajo sobre Economía y Comercio Alternativos) analizó las implicaciones ambientales de los acuerdos comerciales, incluyendo el TLCAN.

Pollution Probe participó en el grupo asesor de comercio del gobierno federal, con un representante en el Energy and Chemical SAGIT (SAGIT sobre Energía y Química), y desde julio de 1992 como miembro del International Trade Advisory Committee (Comité Asesor sobre Comercio Internacional). Pollution Probe, CEI.A y Common Frontiers escribieron un documento conjunto (PProbe, CELA y Common Frontiers, 1991) que concluyó que los temas ambientales deberían ser integrados en la formulación de políticas comerciales para asegurar el desarrollo sustentable. Pollution Probe fue el grupo canadiense líder, junto con NWF, en la propuesta de salvaguardas ambientales para ser incluidas en el TLCAN (PProbe $y$ NWF, 1992).

Las principales organizaciones ambientalistas en el debate del TLCAN suscribieron la "Binational Statement on Environmental Safeguards" ("Declaración Binacional sobre Salvaguardas Ambientales"), el 28 de mayo de 1992, que debería incorporarse al TLCAN $^{25}$ (Binational Statement, 1992). Unicamente Energy Probe, un think-tank independiente, consideró el libre comercio como una oportunidad para mejorar los niveles ambientales canadienses y vio al ALCEUC como una oportunidad para terminar con los subsidios en el sector energético.

La Canadian Environmental Law Association, un grupo ambiental de interés público fundado en 1970 y actualmente financiado por el Ontario Legal Aid Plan (Plan de Ayuda Legal de Ontario), fue el catalizador en el debate del libre comercio al proporcionar el principal análisis legal ambiental sobre el que los grupos ambientales canadienses se organizaron frente al ALCEUC (CELA, 1988 y 1991), el GATT (CELA, 1990) y el TLCAN (CELA, 1993). CELA es un miembro de la Ontario Coalition for Social Justice

${ }^{25}$ Pollution Probe, Canadian Environmental Law Association, Greenpeace, Rawson Academy of Aquatic Sciences, Cultural Survival-Canada (Sobrevivencia Cultural de Canadá), Sierra Club Canada y Friends of the Earth Canada (Amigos de la Tierra Canadá). 
(Coalición de Justicia Social de Ontario) - originalmente Coalition Against Free Trade- y de la Action Canada Network.

Greenpeace desarrolló estrategias en los ámbitos internacional y continental para oponerse a las agendas políticas y económicas del ALCEUC, el TLCAN, el GATT, el FMI, y el Banco Mundial que afectarían al medio ambiente (Greenpeace, 1993). La Rawson Academy of Aquatic Sciences, una red informal de científicos preocupados por las amenazas al ecosistema acuático de Canadá, se involucró en el debate del libre comercio en lo relacionado con las exportaciones de agua dulce a los Estados Unidos. Cultural Survival Canada insistió que los acuerdos comerciales deberían proteger las culturas indígenas y el ambiente natural donde habitan, y trabajó con grupos ambientalistas como CEN, CELA, Pollution Probe y Rawson Academy of Aquatic Sciences. Sierra Club of Canada y Friends of the Earth Canada empezaron a participar hacia el final de las negociaciones del TLCAN

\section{Posiciones ambientalistas frente al TLCAN y la cCA}

Las posiciones ambientalistas canadienses frente al TLCAN y a la Comisión de Cooperación Ambiental de América del Norte (CCA) pueden sintetizarse por medio de los documentos de Pollution Probe y CELA. Janine Ferretti, anterior directora ejecutiva de PProbe, conjuntamente con Steward Hudson, director de la Oficina Internacional de la U.S. National Wildlife Federation (Federación Nacional para la Naturaleza de Estados Unidos), propusieron las siguientes siete salvaguardas ambientales para que fueran incluidasen el texto del TLCAN (PProbe y NWF, 1992):

1. Debería existir un compromiso explícito por parte de los firmantes de que el TLCAN impulsará un desarrollo ambientalmente sustentable y socialmente equitativo, que garantice mejores condiciones para las generaciones futuras que aquellas que disfrutamos actualmente.

2. Las excepciones actuales del GATT contenidas en los artículos XX(b) y XX(g) no deberían incluirse en el TLCAN porque son inadecuadas para enfrentar conflictos potenciales en materia comercial-ambiental. Deberían redactarse excepciones generales en el TLCAN para salvaguardar políticas ambientales legítimas y aclarar que el TLCAN no

puede ser usado para socavar medidas de protección ambiental.

3. Las condiciones para establecer estándares armonizados o equivalentes entre los firmantes del TLCAN no deberían debilitar directa o indirectamente los estándares ambientales internos de cualquier municipio, provincia o país. La armonización de estándares debería ser vista como el "pison, en lugar del "techon. Las jurisdicciones deberían establecer estándares más rigurosos para enfrentar preocupaciones ecológicas específicas o únicas.

4. - Deberían incluirse en el TLCAN condiciones de salvaguardas adecuadas para prevenir el cuestionamiento de acciones destinadas a establecer efectivamente acuerdos internacionales. La obligación de un país bajo esos acuerdos y el derecho de llevar a cabo acciones justificadas para poner en práctica efectivamente esas obligaciones deberían ser garantizados explícitamente en el TLCAN, aun si otros firmantes son parte o no de tal acuerdo.

5. Deberían incluirse condiciones para garantizar que el proceso de solución de controversias del TLCAN genere resultados ambientales benéficas, en lugar de minar los esfuerzos para la protección ambiental. Para asegurar que las decisiones del panel estén informadas, las provisiones del TLCAN deberían garantizar la participación de expertos ambientales en el proceso de solución de controversias, y asegurar la transparencia y la participación pública.

6. Con el fin de garantizar la internalización de costos ambientales, deberían llevarse a cabo medidas para asegurar que las consecuencias ambientales del TLCAN, incluyendo la inversión, sean consideradas. Deberían agregarse provisiones al TLCAN que requieran la aplicación de criterios ambientales a la nueva inversión, tales como el requerimiento del uso de la mejor tecnología disponible, y que garanticen el derecho público a la información sobre el uso de materiales peligrosos en los procesos de producción.

Las condiciones en una cláusula de anexión contenida en el TLCAN que guíen a otros países que pretendan formar parte 
del TLCAN, deberían reflejar las preocupaciones ambientales. Estas condiciones deberían incluir como requerimiento que las investigaciones de impacto ambiental sobre la extensión de las provisiones del TLCAN a un país dado o conjunto de países, sean conducidas en una etapa inicial del proceso de negociaciones.

Michelle Swenarchuk, directora ejecutiva de CELA, coordinó un análisis legal sobre las implicaciones ambientales del TLCAN y preparó un reporte final para el Ministerio de Medio Ambiente y Energía de Ontario (Swenarchuk, 1993:131), en el que hizo las siguientes observaciones:

1. El TLCAN perpetúa los problemas ambientales del ALCEUC y crea algunos nuevos.

2. A pesar de que proporciona protección parcial a las acciones comerciales tomadas de conformidad con tres acuerdos ambientales internacionales, la protección es limitada.

3. El acuerdo no evita que los países reduzcan los estándares ambientales o su ejecución para atraer inversiones.

4. El TLCAN no resuelve los problemas relacionados con las estrategias para la conservación de los recursos que derivan de los requerimientos del trato nacional, la "cláusula de la proporcionalidad", y las decisiones del panel comercial del GATT y el ALCEUC. Estas barreras a las políticas de conservación afectan a todos los recursos canadienses incluyendo el agua.

5. El acuerdo instituye una nueva aproximación al establecimiento de estándares ambientales diferente de las prácticas actuales en Canadá y Ontario. Muchos estándares son establecidos por cuerpos internacionales sin responsabilidad social, y no existen en el TLCAN las condiciones para que se dé la participación pública en el proceso. Los derechos de los gobiernos nacionales y provinciales para establecer estándares más estrictos son limitados. El TLCAN codifica pruebas usadas en paneles comerciales previos (tales como la prueba de "necesidad"), que han derivado en la disminución de estándares ambientales.

6. Los requerimientos de notificación y consulta para los gobiernos federal y de Ontario pueden tener implicaciones de recursos considerables.

7. Las disputas de subsidios entre Canadá y los Estados Unidos no están consignadas o resueltas en el TLCAN.

8. Los procesos de solución de controversias en el TLCAN son secretos y no proporcionan ningún derecho de acceso a los gobiernos provinciales ni al público.

El TLCAN fue negociado por la administración Bush, pero la propuesta del gobierno de Clinton fue favorecer la aprobación de TLCAN con acuerdos paralelos sobre temas laborales y ambientales. Tanto en Canadá como en México y los Estados Unidos, los grupos ambientalistas contribuyeron con observaciones a esta segunda etapa de negociaciones.

La ambientalista canadiense Janine Ferretti, directora ejecutiva de Pollution Probe, propuso una Comisión de Cooperación Ambiental de América del Norte con poderes para: intervenir en la actuación ambiental de los tres países, investigar quejas ciudadanas, asegurar la aplicación de leyes ambientales internas y acuerdos internacionales, monitorear problemas emergentes, y facilitar la transferencia de tecnologías y el acceso a fondos para la protección ambiental. También propuso que esa comisión tuviera funciones relacionadas con las provisiones ambientales del TLCAN y que se involucrara en los procesos del panel de solución de controversias bajo el acuerdo (Ferretti, 1993).

La mayoría de los ambientalistas canadienses consideraron que la comisión propuesta no podría resolver los problemas ambientales causados por el TLCAN. En una carta dirigida a Michael Wilson, entonces ministro de Comercio Internacional, ochenta grupos ambientalistas canadienses, con la participación de CELA, se 
opusieron al acuerdo paralelo y a la Comisión de Cooperación Ambiental de América del Norte:

\section{La negociación de los acuerdos paralelos y el establecimiento de la Comisión representan una pantalla de humo, que pretende encubrir el hecho de que los objetivos de la politica coenc del TLCAN son incompatibles fundamentmente comercial objetivos ambientales [...] La creación de una nueva burocracia ambiental para dirigir y comentar las consecuencias ambientales desastrosas del TLCAN, como se describe en el texto, no es de utilidad. Dado el contenido del TLCAN, no es posible que una Comisión corrija sus problemasecológicosfundamentales (CELA et al., 1993).}

Los acuerdos paralelos contienen pocos elementos propuestos por los ambientalistas canadienses y sus contrapartes estadounidenses y mexicanos (Gallardo, 1993). En su primer año de operación, la Comisión de Cooperación Ambiental de América del Norte ${ }^{26}$ se centró principalmente en desarrollar sistemas de información, una biblioteca, bases de datos sobre derecho ambiental en los tres países, e indicadores ambientales. El programa y las actividades de la CCA están dirigidos por un Consejo de Ministros del medio ambiente y tiene un Comité Consultivo Público Conjunto con cinco representantes de cada país. El ACAAN estableció dos canales para presentar denuncias sobre la falta de aplicación de las leyes ambientales. ${ }^{27}$ Las denuncias públicas o no gubernamentales se limitan al primer canal, que concluye con la preparación de un expediente de hechos para los ministros, y tarda por lo menos dos años terminarlo.

A la fecha, sólo dos peticiones han sido aceptadas: el caso sobre la muerte masiva de aves migratorias en la presa Silva en México y la construcción de un muelle en la isla Cozumel. Dos peticiones presentadas por organizaciones estadounidenses no fueron aceptadas para su revisión porque implicaban acciones del Capitolio que suspendían la aplicación de leyes existentes en los Estados Unidos. La comisión dictaminó que no tenía el mandato para investigar las acciones del Congreso, aun si se pretendía disminuir

${ }^{6}$ Ia sede de la CCA está en Montreal, y tiene un equipo de 30 personas y un presupuesto de 10.6 millones de dólares.

z I I definición de una ley ambiental excluye cualquier repulación o estatuto cuyo propósito primario sea manejar la agricultura comercial o la explotación de los recursos la protección ambiental. El papel de la CCA está limitado al intercambio de información y a la cooperación.

Los grupos ambientalistas canadienses estuvieron de acuerdo en que la firma del TLCAN, a pesar de ser el acuerdo comercial "más verde" hasta la fecha, aceleró las presiones para la desregulación. Ahora están preocupados por mantener, tanto como sea posible, la actual estructura de regulación ambiental frente a las fuertes presiones corporativas (CCPA et al., 1996).

\section{Reflexiones finales}

En los años sesenta y setenta hubo un crecimiento extraordinario de los nuevos movimientos sociales tales como los de ambientalistas, de la mujer, de derechos civiles, y en favor de la paz, en los países altamente industrializados. Han tenido un fuerte impacto en la sociedad y han desarrollado nuevas formas de acción política y social.

La teoría de los nuevos movimientos sociales (Touraine, 1983 y 1977; Melucci, 1989; Habermas, 1989) concibe los nuevos movimientos sociales como una respuesta a nuestros tiempos. Considera que los sistemas políticos y sociales son cada vez más tecnocráticos y burocráticos, restringiendola libertad individual y minando la calidad de vida. El sistema de valores del statu quo cree que el progreso social continúa y que el bienestar material puede seguir creciendo. Frente a esta situación, los nuevos movimientos sociales han tenido más interés en cambiar los valores sociales que en modificar o influir a los gobiernos. Esta teoría también hace una fuerte distinción entre el movimiento laboral -que en la perspectiva marxista dominante era el agente principal del cambio social-y los nuevos movimientos sociales que son percibidos como más participativos y menos materialistas. Considera que el sector labora ha entrado a la estructura social burocratizada y ya no tiene la capacidad de ser el líder del cambio.

La experiencia canadiense en la década pasada contradice parte de este enfoque. El movimiento laboral ha sido un líder de las luchas por el cambio social. Ha tenido un apoyo creciente de los trabajadores canadienses, en todos los sectores, por una perspectiva de "sindicalismo social". Ésta considera que los sindicatos deberían ser activos en un amplio espectro de temas en coalición con otros grupos de movimientos sociales, como lo muestran los procesos del ALCEUC y el TLCAN. En oposición a los postulados de la teoría de 
los nuevos movimientos sociales, en Canadá éstos han dedicado gran parte de su tiempo a actividades de abogacía para cambiar políticas gubernamentales. Pero a diferencia de los partidos políticos, no se han restringido sólo al cambio político sino que también han buscado el cambio de los valores sociales.

Una de las fortalezas de los nuevos movimientos sociales ha sido su definición amplia de política. El trabajo para cambiar los valores sociales y la opinión pública ayuda a crear la presión y el espacio políticos para que los gobiernos actúen; y la promoción de los cambios en las políticas gubernamentales sirve para educar y politizar a la gente de la sociedad civil. Las coaliciones que permanecen juntas y aprenden de la experiencia de trabajar unidas en temas diversos experimentan el fortalecimiento de su actividad política. La Action Canada Network fue un buen ejemplo de una coalición que tuvo la capacidad de mantener un nivel de interacción entre sus grupos multisectoriales, que cambió sus concepciones por medio de su movilización frente al ALCEUC y al TLCAN. En este contexto, el éxito del movimiento ambientalista canadiense y sus contrapartes mexicana y estadounidense, fue su contribución para lograr que los gobiernos reconocieran públicamente la existencia de implicaciones mutuas entre la integración comercial de América del Norte y la naturaleza global de los problemas ambientales.

Los temas tradicionales de las negociaciones gubernamentales de comercio internacional fueron sobrepasados por las demandas ambientales y sociales de un nuevo movimiento trinacional. Por primera vez, los grupos ambientalistas se movilizaron con firmeza para influir en la política de comercio internacional de sus gobiernos, hasta entonces fuera del alcance de la ciudadanía. E resultado más importante del TLCAN, desde la perspectiva de la sociedad civil, fue el surgimiento de grupos y coaliciones ambientalistas, así como redes multisectoriales en los tres países, y la conformación de alianzas trinacionales con el objetivo de tener acceso a la información y a participar en la toma de decisiones tanto del proceso de negociaciones como de la ejecución del acuerdo.

Las organizaciones ecologistas consideraron al ACAAN como una oportunidad para influir en la formulación de políticas ambientalestrinacionales. Noobstante,sus propuestas fundamentales no fueron incorporadas: mínimos ambientales, procesos productivo limpios, protección a los recursos naturales, e internalización de costos ambientales. Afirmaron que el ACAAN no establece obligaciones nuevas sobre la conservación de recursos naturales, la agricultura sustentable, la prevención o reducción de la contaminación, la eliminación o el control de tóxicos, la salud y seguridad de los trabajadores y ciudadanos en general, ni pleno acceso del público a la información relacionada con el medio ambiente. Además, toda obligación se limita al territorio de las partes, excluyendo aquellos problemas comunes a los tres (como el aire y los océanos)

Un logro importante del debate sobre el ACAAN es que se reconoció la necesidad de plantear la constitución de un régimen ecológico regional que esté asociado a las pautas de desarrollo imperantes. Asimismo, fue particularmente significativo porque planteó problemas de manejo ambiental cuya solución exige la acción coordinada de los gobiernos y de las organizaciones sociales interesadas en los problemas ecológicos, con la perspectiva de lograr un desarrollo sustentable en toda el área de América del Norte. 
Tabla 1

Características de grupos nacionales canadienses

\begin{tabular}{|c|c|c|c|c|c|}
\hline Grupos & Filosofia & Tácticas primarias & $\begin{array}{c}\text { Presupuesto en } \\
\text { dólares } \\
\text { canadienses } \\
\text { (1991) }\end{array}$ & $\begin{array}{l}\text { Miembros y } \\
\text { partidarios }\end{array}$ & Asuntos \\
\hline $\begin{array}{l}\text { Nature } \\
\text { Conservacy of } \\
\text { Canada }\end{array}$ & $\begin{array}{l}\text { Conservacionismo } \\
\text { Naturalismo }\end{array}$ & $\begin{array}{l}\text { Protección del } \\
\text { hábitat natural }\end{array}$ & 2.3 millones & Muy pocos & $\begin{array}{l}\text { Manejo de la } \\
\text { tierra }\end{array}$ \\
\hline $\begin{array}{l}\text { Canadian } \\
\text { Nature } \\
\text { Federation }\end{array}$ & Conservacionismo & $\begin{array}{l}\text { Abogacía, } \\
\text { cabildeo, } \\
\text { educación, } \\
\text { política }\end{array}$ & 1,051 millones & $\begin{array}{l}20,000 \text { miembros } \\
\text { y } 20,000 \\
\text { partidarios }\end{array}$ & Preserva ón \\
\hline $\begin{array}{l}\text { Canadian Artic } \\
\text { Resource } \\
\text { Committee }\end{array}$ & $\begin{array}{l}\text { Conservacionismo } \\
\text { Ecologismo }\end{array}$ & $\begin{array}{l}\text { Abogacía, } \\
\text { investigación, } \\
\text { educación, } \\
\text { política }\end{array}$ & 500,000 & $\begin{array}{l}5,000 \text { miembros } \\
\text { y } 15,000 \\
\text { partidarios }\end{array}$ & $\begin{array}{l}\text { Derechos } \\
\text { indígenas y } \\
\text { norteños }\end{array}$ \\
\hline $\begin{array}{l}\text { Rawson } \\
\text { Academy of } \\
\text { Aquatic Science }\end{array}$ & $\begin{array}{l}\text { Conservacionismo } \\
\text { Ambientalismo }\end{array}$ & $\begin{array}{l}\text { Abogaúa, } \\
\text { investigación, } \\
\text { política }\end{array}$ & 1 millón & 50 miembros & Manejo del agua \\
\hline $\begin{array}{l}\text { Harmony } \\
\text { Foundation }\end{array}$ & $\begin{array}{l}\text { Desarrollo } \\
\text { sustentable }\end{array}$ & $\begin{array}{l}\text { Educación, } \\
\text { diálogo }\end{array}$ & $?$ & Nïnguno & $\begin{array}{l}\text { Reforma por } \\
\text { medio de la } \\
\text { educación }\end{array}$ \\
\hline
\end{tabular}

continuación..

\begin{tabular}{|l|l|l|l|l|l|}
\hline $\begin{array}{l}\text { Sierra Club } \\
\text { Canada }\end{array}$ & Conservacionismo & $\begin{array}{l}\text { Abogacía, } \\
\text { cabildeo, turismo } \\
\text { ecológico }\end{array}$ & $?$ & $\begin{array}{l}500,000 \\
\text { partidarios y } \\
\text { miembros en los } \\
\text { Estados Unidos } \\
\text { y Canadá }\end{array}$ & $\begin{array}{l}\text { Preservación y } \\
\text { temas indígenas }\end{array}$ \\
\hline Energy Probe & Ambientalismo & $\begin{array}{l}\text { Abogacía, } \\
\text { investigación, } \\
\text { política, } \\
\text { monitoreo }\end{array}$ & 575,000 & $\begin{array}{l}20,000 \\
\text { partidarios }\end{array}$ & $\begin{array}{l}\text { manejo de la } \\
\text { energía }\end{array}$ \\
\hline $\begin{array}{l}\text { World Wildlife } \\
\text { Fund Canada }\end{array}$ & $\begin{array}{l}\text { Ambientalismo } \\
\text { Amservacionismo }\end{array}$ & $\begin{array}{l}\text { Abogacía, } \\
\text { cabildeo, } \\
\text { educación, } \\
\text { política }\end{array}$ & 6.2 millones & $\begin{array}{l}28 \text { organizacio- } \\
\text { nes nacionales y } \\
50,000 \text { miembros } \\
\text { en Canadá }\end{array}$ & $\begin{array}{l}\text { Preservar lábitat } \\
\text { salva y el }\end{array}$ \\
\hline $\begin{array}{l}\text { Canadian } \\
\text { Wildlife } \\
\text { Federation }\end{array}$ & $\begin{array}{l}\text { Conservacionisrno } \\
\text { Desarrollo } \\
\text { sustentable }\end{array}$ & $\begin{array}{l}\text { Cabildeo, litigio, } \\
\text { educación }\end{array}$ & 11.4 millones & $\begin{array}{l}620,000 \\
\text { miembros y } \\
\text { partidarios }\end{array}$ & Usos múltiples \\
\hline $\begin{array}{l}\text { Ducks } \\
\text { Canadimited }\end{array}$ & Conservacionismo & $\begin{array}{l}\text { Educación, } \\
\text { investigación, } \\
\text { actividades con } \\
\text { corporaciones }\end{array}$ & 48 millones & $\begin{array}{l}\text { 135,000 } \\
\text { partidarios }\end{array}$ & $\begin{array}{l}\text { Usos múltiples } \\
\text { manejo del } \\
\text { hábitat }\end{array}$ \\
\hline
\end{tabular}




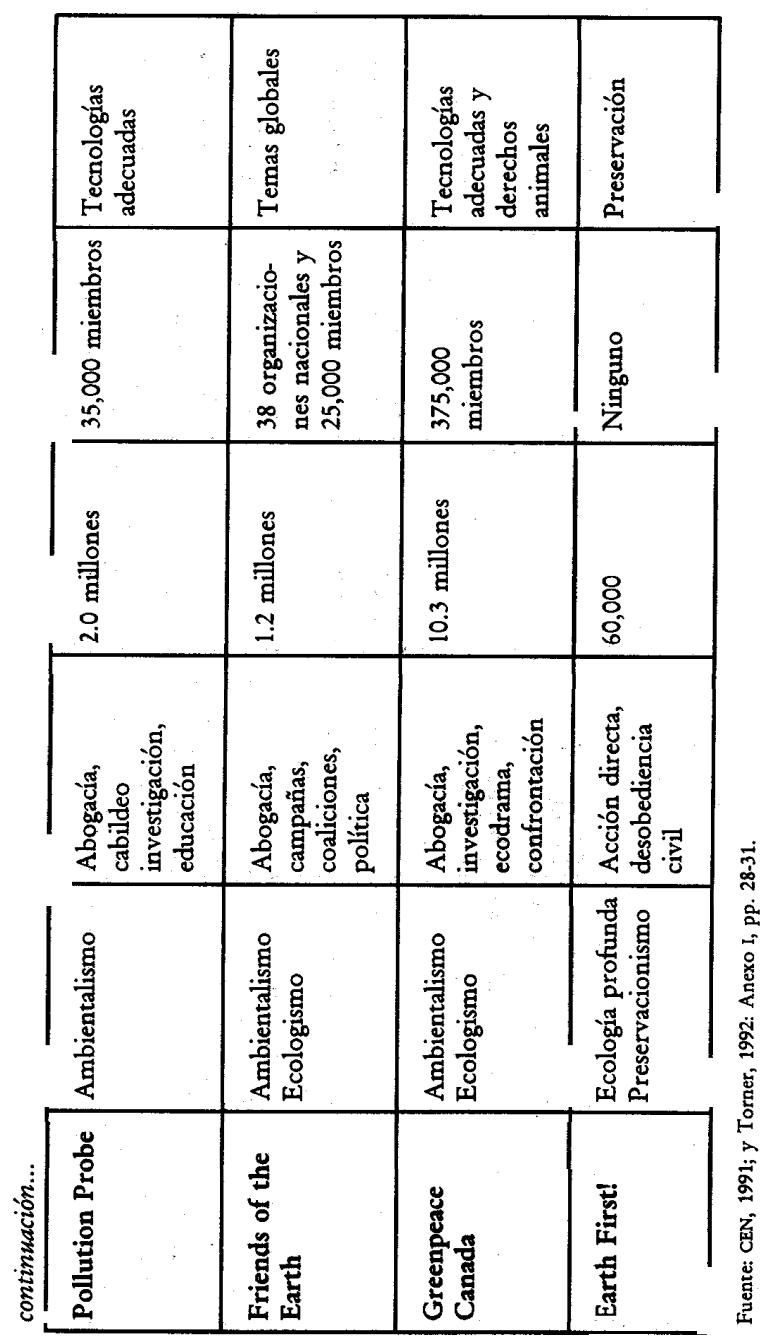

\section{Acrónimos}

ACAAN Acuerdo de Cooperación Ambiental de América del Norte

ACN Action Canada Network (Red Canadiense de Acción)

ALCEUC Acuerdo de Libre Comercio de Estados Unidos y Canadá

BCNI Business Council on National Issues (Consejo Empresarial de Asuntos Nacionales)

CCA

Comisión de Cooperación Ambiental de América del Norte

CCPA Canadian Center for Policy Alternatives (Centro Canadiense de Políticas Alternativas)

CELA Canadian Environmental Law Association (Asociación Canadiense sobre Ley Ambiental)

CEN

Canadian Environmental Network (Red Ambiental Canadiense)

$\begin{array}{ll}\text { COC } & \text { Council of Canadians (Consejo de Canadienses) } \\ \text { FOEC } & \text { Friends of the Earth Canada (Amigos de la Tierra }\end{array}$ Canadá)

GATT General Agreement on Tariffs and Trade (Acuerdo General de Aranceles y Comercio)

IAC-CELA International Affairs Caucus, Canadian Environmental Law Association(Grupo de Asuntos Internacionales, Asociación Canadiense sobre Ley Ambiental)

FMI Fondo Monetario Internacional

NTFEE National Task Force on Environment and Economy (Grupo de Trabajo Nacional sobre Medio Ambiente y Economía)

NWF National Wildlife Federation (Federación Nacional para la Naturaleza)

Partido Acción Nacional

PAN

PCN

PProbe

Pro-Canada Network (Red Pro-Canadá)

Pollution Probe (Investigación sobre Contaminación)

RMALC Red Mexicana de Acción frente al Libre Comercio TLCAN Tratado de Libre Comercio de América del Norte TWS Temagami Wilderness Society (Sociedad Temagami para la Naturaleza) 
UNCED United Nations Conference on Environment and Development (Conferencia de las Naciones Unidas sobre el Ambiente y el Desarrollo)

wCWC Western Canada Wilderness Committee (Comité para la Naturaleza de Canadá Occidental)

\section{Bibliografía}

Altmeyer, George (1976), "Three Ideas of Nature in Canada, 18931914”, Journal of Canadian Studies, vol. XI, núm. 3, agosto.

Barr, Jane (1995), "The Origins and Emergence of Quebec's Environmental Movement: 1970-1985”, Montreal, Departamento de Geografía/Universidad de McGill, tesis de maestría.

Binational Statement (1992), "Binational Statement on Environmental Safeguards that should be Included in the NAFTA", 28 de mayo.

Brundtland, Gro H. (1987), Our Common Future, World Commission on Environment and Development, Oxford y Nueva York, Oxford University Press.

CELA (Canadian Environmental Law Association) (1993), The Environmental Implications of Trade Agreements, preparado para el Ministerio de Medio Ambiente y Energía de Ontario, Toronto, Queen's Printer for Ontario.

(1991), "Environmental Assessment of the First Two Years of the CUFTA", enero.

(1990), "International Trade and the Environment: An Environmental Assessment of GATT", marzo.

(1988), "Environmental Impacts of the Canada-U.S. FTA", resumen preparado para el Comité Representante de Asuntos de Finanzas y Economía, adjunto al boletín de prensa del 5 de marzo.

- et al. (1993), Carta dirigida al ministro de Comercio Internacional, Michael Wilson, suscrita por ochenta organizaciones ambientalistas canadienses, Ontario, 5 de mayo.

CCPA (Canadian Center for Policy Alternatives) (1992), "Popular Sector Organizations and Trade", Reporte para el Ministerio 
Melucci (1989), Nomads of the Present: Social Movements and Individual Needs in Contemporary Society, Filadelfia, Temple University Press.

Nicholson, M. (1970), The Environmental Revolution: A Guide for the New Masters of the World, Londres, Hodder \& Stoughton.

Paehlke, Robert (1989), Environment and the Future of Progressive Politics, New Haven, Yale University Press.

Pearce, F. (1991), Green Wawiors: The People and the Politics Bebind the Environmental Revolution, Londres, Bodley Head.

PProbe (Pollution Probe) y National Wildlife Federation, U.S. (1992), "Minimal Environmental Safeguards to be included in the NAFTA", Washington D. C., junio.

PProbe, CELA y Common Frontiers (1991), "International Trade and the Environment", Ottawa, octubre.

Sale, K. (1993), The Green Revolution: The American Environmental Movement, 1962-1992, Nueva York, Hill \& Wang.

Shrybman, Steven (1991), "Selling the Environment Short", CELA, Informe núm. 189, Toronto, enero.

(1990) "Free Trade vs. the Environment: The Implications of GATT", The Economist, vol. 20, núm. 1, enero-febrero.

Swenarchuk, Michelle (1993), "The Environmental Implications of NAFTA: A Legal Analysis", en The Environmental Implications of Trade Agreements, Reporte final preparado por la Canadian Environmental Law Association para el Ministerio de Ambiente y Energía de Ontario, agosto.

Toner, Glen (1992), "The Canadian Environmental Movement: A Conceptual Map", Ottawa, Department of Political Science/Carleton University.

Touraine, Alain (1983), Anti-Nuclear Protest: The Opposition to Nuclear Energy in France, Londres, Cambridge University.

(1977), The Self Production \& Society, Chicago, University of Chicago. 
de Industria, Comercio y Tecnología, Gobierno de Ontario, julio.

, Common Frontiers, y Action Canada Network (1996), "Challenging 'Free Trade' in Canada: The Real Story", agosto.

CEN (Canadian Environmental Network) (1991), The Green List: A Guide to Canadian Environmental Organizations \&Agencies, Toronto, lera. Ed.

Campbell, Bruce (1992), "Which Way for the Americas", Canadian Center for Policy Alternatives, noviembre.

Dalton, Russell J. y Manfred Kuechler (comps.) (1992), Los nuevos movimientos sociales, Valencia, Ediciones Alfons el Magnánim, Generalitat Valenciana.

Etzioni-Halevy, E. (1990), "The Relative Autonomy of Elites. The Absorption of Protest and Social Progress in Western Democracies", en J. C. Alexander y P. Sztompka (eds.), Rethinking Progress: Movements, Forces and Ideas at the End ff the 20th Century, Boston, Unwin Hyman.

Ferretti, Janine (1993), "Elements of an Effective North American Commission on the Environment", Ottawa, 4 de marzo.

Gallardo, Sofía (1997), "Participación ciudadana frente a los riesgos ambientales de la globalización y el TLCAN", en María Teresa Gutiérrez Haces y Daniel Hiernaux-Nicolas (coords.), En busca de nuevos vínculos: Globalización y reestructuración territorial en las Américas, México, Universidad Autónoma Metropolitana-Unidad Xochimilco, e Instituto de Investigaciones Económicas/Universidad Nacional Autónoma de México.

(1995), "Movimiento ciudadano: globalización y Tratado de Libre Comercio de América del Norte", Estudios Sociológicos, vol. XIII, núm. 39, septiembre-diciembre.
(1994), "Environmentalists's Views on NAFTA: Sovereignty and Sustainable Development", Voices đ Mexico, núm. 29, Centro de Investigaciones de América del Norte/Universidad Nacional Autónoma de México, octubre-diciembre.

(1993), "El debate sobre el Acuerdo de Cooperación Ambiental", Estados Unidos: Informe Trimestral, vol. m, núm. 4, División de Estudios Internacionales/Centro de Investigación y Docencia Económicas, invierno.

Gallon, Gary (1991), "Repon on the Nature and Make Up of the Key Environment and Conservation Organizations in Canada”, Ottawa, Canadian Environmental Network, julio.

Greenpeace (1993), "UNCED Underrnined: Why Free Trade Won't Save the Planet", Washington, D. C.

Greenprint for Canada Committee (1989), "Greenprint for Canada: A Federal Agenda for the Environment ${ }^{\mathrm{n}}$, Ottawa, junio.

Habermas, Jürgen (1989), Towards a Rational Society, Londres, Polity Press.

Harries-Jones, P. (1993), "Between Science and Shamanism: The Advocacy of Environmentalismin Toronto ${ }^{n}$, en Kay Milton (ed.), Environmentalism: The View from Anthropology, Londres, Estados Unidos y Canadá, Routledge.

(ed.) (1991), Making Knowledge Count: Advocacy and Social Science, Montreal y Kingston, McGill-Queen's Press.

Macdonald, Doug (1991), The Politics of Pollution, Toronto, McClelland \& Stewart.

McInnes, Craig (1989), "Environment groups face a crisis of identity", The Globe $\mathcal{E}$ Mail, 15 de julio.

Manes, C. (1990), Green Rage: Radical Environmentalism and the Unmaking of Civilization, Boston, Little Brown. 